\title{
Movement during focused ultrasound therapy caused by an unstable magnetic resonance table: case report
}

\author{
Kazuaki Yamamoto, MD, ${ }^{1,2}$ Hisashi Ito, MD, PhD, ${ }^{3}$ Shigeru Fukutake, MD, ${ }^{3}$ Takashi Odo, MD, ${ }^{3}$ \\ Tetsumasa Kamei, MD, ${ }^{3}$ Toshio Yamaguchi, MD, PhD, ${ }^{4}$ and Takaomi Taira, MD, PhD ${ }^{1}$

\begin{abstract}
1Department of Neurosurgery, Tokyo Women's Medical University, Tokyo; 2 Department of Neurosurgery, Shonan Kamakura General Hospital, Kamakura; ${ }^{3}$ Department of Neurology, Shonan Fujisawa Tokushukai Hospital, Fujisawa; and ${ }^{4}$ Research Institute of Diagnostic Imaging, Shin-Yurigaoka General Hospital, Kawasaki, Japan
\end{abstract}

\begin{abstract}
Transcranial MR-guided focused ultrasound (MRgFUS) therapy is a less invasive form of stereotactic treatment for tremors and other movement disorders. Its stereotactic accuracy is ensured by stability of the stereotactic frame and MR table. The authors report a case wherein the patient's movement was detected, and the MR images were repeated to continue the treatment.

A 72-year-old man with essential tremor underwent unilateral ventralis intermedius thalamotomy using MRgFUS. The stereotactic frame was correctly fixed to the patient's skull and the table. During the seventh sonication, the patient pressed the emergency button and vomited several times. Before the eighth sonication, the patient's movement was detected and was verified on coronal images. The MR images were repeated, and the treatment was successfully completed with significant improvement in the tremors. After treatment, it was discovered that the MR table was laterally unstable due to the absence of ball bearings, which should be present on both sides of the guide rail of the MR table. The ball bearings were attached to the reverse side of the table, and the table was stabilized. Stereotactic accuracy of MRgFUS is not only ensured by rigid fixation of the stereotactic frame, but also by stability of the MR table.

https://thejns.org/doi/abs/10.3171/2020.4.JNS20219
\end{abstract}

KEYWORDS focused ultrasound therapy; instability; magnetic resonance table; movement detection; stereotactic accuracy; functional neurosurgery

$\mathrm{T}$ RANSCRANIAL MR-guided focused ultrasound (MRgFUS) therapy is an emerging less invasive form of stereotactic treatment for movement disorders. ${ }^{1-4}$ Stability of the devices used for stereotactic therapies, including MRgFUS, is essential for procedural accuracy. ${ }^{5-13}$ Rigid fixation of the stereotactic frame to the MR table ensures stereotactic accuracy of the FUS. Furthermore, quality assurance procedures are routinely performed on the day of as well as 1 day before the procedure to ensure that the system is functioning correctly. The movement detection function of the system reveals any unacceptable movement before each sonication so that targets in the cerebrum can be ablated accurately. We herein report a case in which movement was detected, and the MR images were repeated to continue the treatment.

\section{Case Report}

History and Presentation

A 72-year-old man with tremors in both hands present- ed to our department. The tremors began approximately 7 years before presentation, and handling chopsticks gradually became difficult. Neurological examination revealed postural and kinetic tremors dominant in the right hand. The total and right-hand (part A + B) scores on the Clinical Rating Scale for Tremor were 75 and 22, respectively, ${ }^{14}$ and the patient was diagnosed with essential tremor. The classic medications prescribed for such cases, including arotinolol and clonazepam, were not effective. Stereotactic treatment options were suggested, and he chose FUS to treat the tremors of his right hand.

\section{MRgFUS Procedure}

The patient underwent MRgFUS for unilateral ventralis intermedius thalamotomy with the Exablate Neuro system (InSightec) in combination with a 1.5T MRI system (Signa HDx, GE Healthcare). The daily quality assurance procedures performed before every treatment showed no abnormality. The stereotactic frame was correctly fixed to the patient's skull and was rigidly fixed to the table. The 

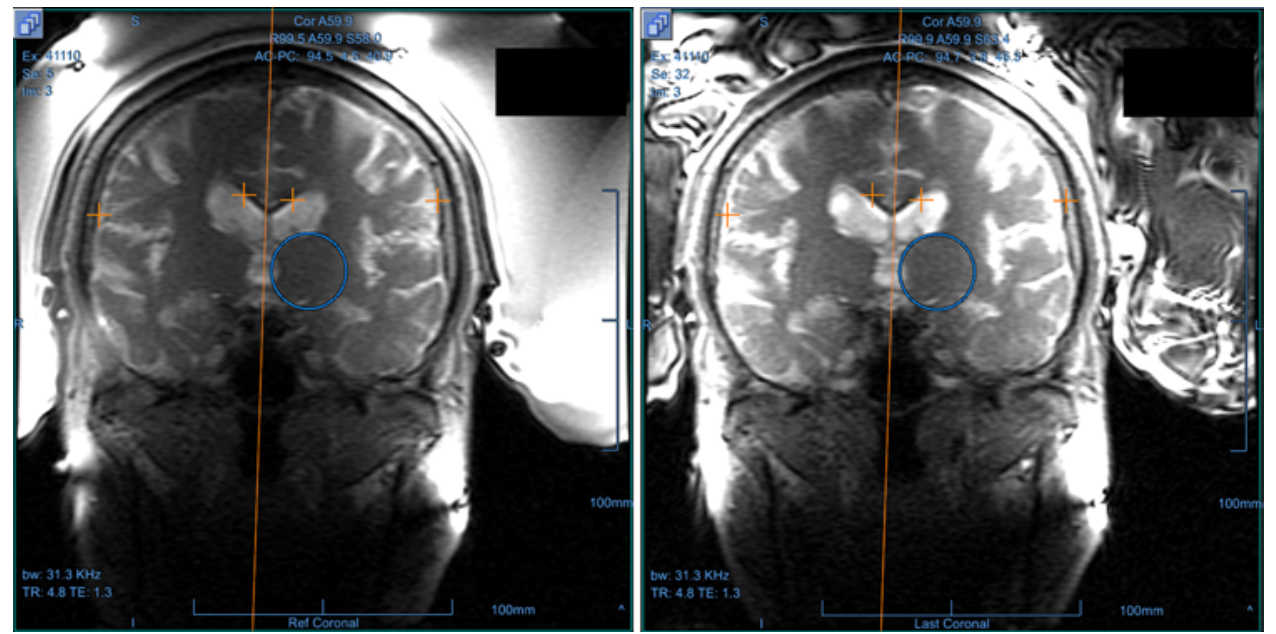

FIG. 1. Coronal MR images revealing the patient's movement. The movement is evident in the image taken immediately before the eighth sonication (right) with fiducial discrepancy in comparison with the reference image (left). Figure is available in color online only.

skull density ratio ${ }^{15}$ number of active transducer elements, skull area, and skull volume were $0.40,988,353 \mathrm{~cm}^{2}$, and $277 \mathrm{~cm}^{3}$, respectively. The target was aligned in 5 sonications, and safety and efficacy were verified in 1 sonication. The treatment phase began, and, during the seventh sonication, the patient stopped the procedure by pressing the emergency button and vomited several times when energy of 21,394 $\mathbf{J}$ was delivered to the target, and the heated spot attained the maximum temperature of $57^{\circ} \mathrm{C}$. Before the eighth sonication, the patient's movement was detected by the system and was verified on coronal images (Fig. 1). Rigid fixation of the frame to the head and MR table was confirmed, and the table marker did not show any movement in the superoinferior direction. MR images were repeated to continue the treatment, and the treatment was successfully completed with significant improvement in the tremors.

\section{Postprocedural Course}

The total and right-hand (part A + B) scores on the Clinical Rating Scale for Tremor were 15 and 9, respec- tively, on the immediate posttreatment day. After the treatment, we found that the MR table was unstable in a lateral direction (Video 1).

VIDEO 1. Clip showing instability of the MR table in a lateral direction, which caused the movement during the procedure. The table has been stabilized after the attachment of the ball bearings to the reverse side of the table. The table shift reduced considerably. Copyright Kazuaki Yamamoto. Published with permission. Click here to view.

The instability was caused by the absence of ball bearings, which should be present on both sides of the guide rail of the MR table (Fig. 2 left). The instability of the table led to a shift of approximately $2.0 \mathrm{~mm}$ around the transducer unit, which was measured using a ruler fixed to the table (Fig. 3A and B). The ball bearings were attached to the reverse side of the table (Fig. 2 right), and the table was stabilized (Video 1). The shift around the transducer unit was reduced to about $0.2 \mathrm{~mm}$ (Fig. 3C and D).

\section{Discussion}

Accuracy in any treatment is essential for the preven-
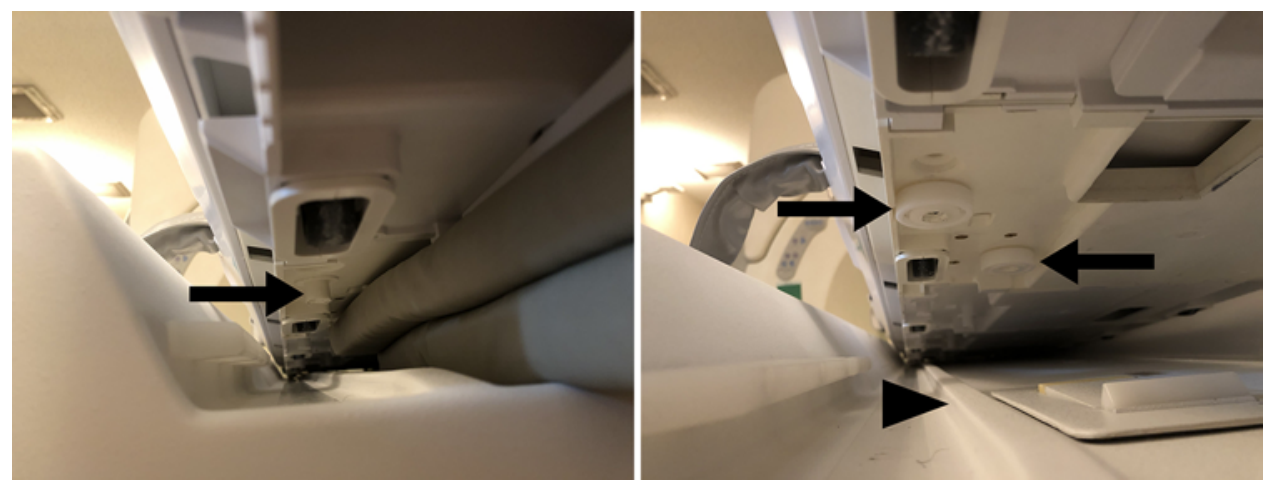

FIG. 2. Photograph showing the absence of the ball bearings (arrow) on the reverse side of the MR table (left). Two ball bearings (arrows) have been attached to catch the rail (arrowhead) and stabilize the table when it slides (right). Figure is available in color online only. 

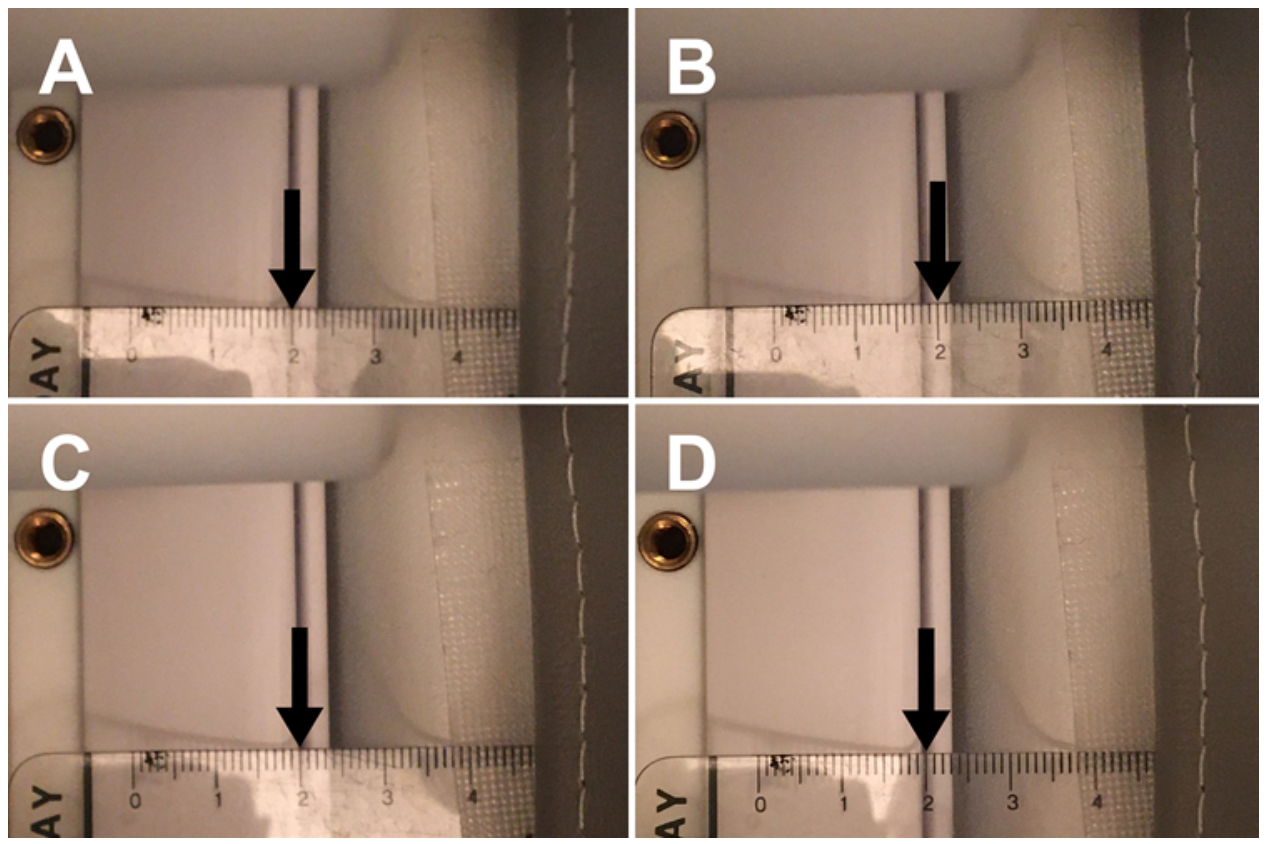

FIG. 3. Photographs showing the table shift before ( $A$ and $B$ ) and after ( $C$ and $D)$ the attachment of ball bearings. The arrows show the same point, where the ruler is fixed to the table, depicting that the 2-mm shift (B) was reduced to $0.2 \mathrm{~mm}(\mathrm{D})$. Figure is available in color online only.

tion of adverse events and for the effective treatment of patients. ${ }^{5-13}$ In this case, the patient's movement was detected despite the rigid fixation of the stereotactic frame. Although the coronal section of the movement-detection images clearly showed movement of the patient during the procedure, the cause of movement could not be determined. After the procedure, the MR table was found to be laterally unstable, which corresponded to the direction of movement revealed on the intraprocedural coronal MR images. It was speculated that the patient's movement was a result of the vomiting after the seventh sonication. No movement of the table was detected prior to this case, during the treatment of the previous 38 cases with MRgFUS completed successfully using the same machine. These cases included patients who vomited during procedures ${ }^{16}$ but movement was not detected possibly because the patients did not move laterally and hence, it was rendered even more difficult for us to notice that the MR table must have moved in this case. In the cases of patients who vomited, delivery of high energy had been required to obtain treatment temperatures because of difficult conditions such as a low skull density ratio..$^{15}$ The patient in the present case also required relatively high energy, which might have been the cause of vomiting. We speculate that the patient's movement, which involved twisting of his body and attempting to roll over, exerted a lateral force on the MR table resulting in its movement; this did not occur in any of the previous cases wherein the patients vomited.

An MR table for FUS is stocked by an FUS manufacturer and is equipped with an FUS system before installation in the respective hospital. In this case, the ball bearings on both sides of the guide rail of the MR table were not attached before stocking from the MR manufacturer.
Since the target coordinates are based on the anterior commissure-posterior commissure plane of the MR images in the planning stage, we must retake MR images and reset target coordinates after images have shown movement. This prolongs the procedure and can impose strain on patients. Consequently, stability of the MR table must always be confirmed.

In conclusion, stereotactic accuracy of FUS is not only ensured by rigid fixation of the stereotactic frame, but also by the stability of the MR table. All MR tables, including those newly installed with an FUS system, should be checked for stability and the presence of ball bearings.

\section{Acknowledgments}

We thank Mr. Hirokazu Nakahodo (InSightec, Inc.) for finding the instability of the MR table.

\section{References}

1. Bauer R, Martin E, Haegele-Link S, et al. Noninvasive functional neurosurgery using transcranial MR imagingguided focused ultrasound. Parkinsonism Relat Disord. 2014;20(suppl 1):S197-S199.

2. Bond AE, Shah BB, Huss DS, et al. Safety and efficacy of focused ultrasound thalamotomy for patients with medicationrefractory, tremor-dominant Parkinson disease: a randomized clinical trial. JAMA Neurol. 2017;74(12):1412-1418.

3. Dobrakowski PP, Machowska-Majchrzak AK, Labuz-Roszak B, et al. MR-guided focused ultrasound: a new generation treatment of Parkinson's disease, essential tremor and neuropathic pain. Interv Neuroradiol. 2014;20(3):275-282.

4. Martin E, Jeanmonod D, Morel A, et al. High-intensity focused ultrasound for noninvasive functional neurosurgery. Ann Neurol. 2009;66(6):858-861.

5. Anheim M, Batir A, Fraix V, et al. Improvement in Parkin- 
son disease by subthalamic nucleus stimulation based on electrode placement: effects of reimplantation. Arch Neurol. 2008;65(5):612-616.

6. Baron MS, Vitek JL, Bakay RAE, et al. Treatment of advanced Parkinson's disease by posterior GPi pallidotomy: 1-year results of a pilot study. Ann Neurol. 1996;40(3):355366.

7. Dogali M, Fazzini E, Kolodny E, et al. Stereotactic ventral pallidotomy for Parkinson's disease. Neurology. 1995;45(4):753-761.

8. Ellis TM, Foote KD, Fernandez HH, et al. Reoperation for suboptimal outcomes after deep brain stimulation surgery. Neurosurgery. 2008;63(4):754-761.

9. Hamani C, Lozano AM. Hardware-related complications of deep brain stimulation: a review of the published literature. Stereotact Funct Neurosurg. 2006;84(5-6):248-251.

10. Iacono RP, Shima F, Lonser RR, et al. The results, indications, and physiology of posteroventral pallidotomy for patients with Parkinson's disease. Neurosurgery. 1995;36(6):1118-1127.

11. Laitinen LV, Bergenheim AT, Hariz MI. Leksell's posteroventral pallidotomy in the treatment of Parkinson's disease. $J$ Neurosurg. 1992;76(1):53-61.

12. Okun MS, Tagliati M, Pourfar M, et al. Management of referred deep brain stimulation failures: a retrospective analysis from 2 movement disorders centers. Arch Neurol. 2005;62(8):1250-1255.

13. Richardson RM, Ostrem JL, Starr PA. Surgical repositioning of misplaced subthalamic electrodes in Parkinson's disease: location of effective and ineffective leads. Stereotact Funct Neurosurg. 2009;87(5):297-303.

14. Fahn S, Tolosa E, Marin C. Clinical rating scale for tremor. In: Jankovic J, Tolosa E, eds. Parkinson's Disease and Movement Disorders. 2nd ed. Williams \& Wilkins; 1993:225-234.
15. Chang WS, Jung HH, Zadicario E, et al. Factors associated with successful magnetic resonance-guided focused ultrasound treatment: efficiency of acoustic energy delivery through the skull. J Neurosurg. 2016;124(2):411-416.

16. Ito H, Fukutake S, Yamamoto K, et al. Magnetic resonance imaging-guided focused ultrasound thalamotomy for Parkinson's disease. Intern Med. 2018;57(7):1027-1031.

\section{Disclosures}

The authors report no conflict of interest concerning the materials or methods used in this study or the findings specified in this paper.

\section{Author Contributions}

Conception and design: Yamamoto, Ito. Acquisition of data: Yamamoto, Fukutake, Odo. Analysis and interpretation of data: Yamamoto, Ito. Drafting the article: Yamamoto. Critically revising the article: Ito. Reviewed submitted version of manuscript: Ito, Fukutake, Odo, Kamei, Yamaguchi, Taira. Approved the final version of the manuscript on behalf of all authors: Yamamoto.

\section{Supplemental Information \\ Videos}

Video 1. https://vimeo.com/410978558.

\section{Correspondence}

Kazuaki Yamamoto: Tokyo Women's Medical University, Tokyo, Japan. straight.through.my.life@gmail.com. 